\title{
Erratum to: The contribution of fMRI to elucidate the pathophysiology of primary headaches
}

\author{
Gennaro Bussone
}

Published online: 24 August 2011

(C) Springer-Verlag 2011

Erratum to: Neurol Sci 32 (Suppl 1):S41-S43,

DOI 10.1007/s10072-011-0557-9

In the published original article, paragraph "The hyperactivity of these areas ...", the word "hypoactivity" has been erroneously typed "hyperactivity".

Therefore, the correct sentence should read:

"Preliminary data by our group on chronic migraineurs without analgesic abuse also show no fMRI hypoactivity in these areas of the lateral pain system."

The online version of the original article can be found under doi:10.1007/s10072-011-0557-9.

G. Bussone $(\bowtie)$

Fondazione IRCCS Istituto Neurologico C. Besta,

Via Celoria 11, 20133 Milan, Italy

e-mail: bussone@istituto-besta.it 